\title{
VEGFR and Type-V RTK Activation and Signaling
}

\author{
Masabumi Shibuya ${ }^{1,2}$ \\ ${ }^{1}$ Jobu University, Isesaki, Gunma 372-8588, Japan \\ ${ }^{2}$ Department of Molecular Oncology, Tokyo Medical and Dental University, Bunkyo-ku, \\ Tokyo 113-8519, Japan \\ Correspondence: shibuya@ims.u-tokyo.ac.jp
}

\begin{abstract}
Vascular endothelial growth factor receptors (VEGFRs) in vertebrates play essential roles in the regulation of angiogenesis and lymphangiogenesis. VEGFRs belong to the receptor-type tyrosine kinase (RTK) supergene family. They consist of a ligand-binding region with seven immunoglobulin (7 Ig) -like domains, a trans-membrane (TM) domain, and a tyrosine kinase (TK) domain with a long kinase insert (KI) (also known as a type-V RTK). Structurally, VEGFRs are distantly related to the members of the M-colony stimulating factor receptor/plateletderived growth factor receptor (CSFR)/(PDGFR) family, which have five immunoglobulin (5 lg)-like domains. However, signal transduction in VEGFRs significantly differs from that in M-CSFR/PDGFRs. VEGFR2, the major signal transducer for angiogenesis, preferentially uses the phospholipase $C \gamma$-protein kinase C (PLC- $\gamma$-PKC)-MAPK pathway, whereas M-CSFR/ PDGFRs use the PI3 kinase-Ras-MAPK pathway for cell proliferation. In phylogenetic development, the VEGFR-like receptor in nonvertebrates appears to be the ancestor of the 7 Igand 5 Ig-RTK families because most nonvertebrates have only a single 7 Ig-RTK gene. In mammals, VEGFRs are deeply involved in pathological angiogenesis, including cancer and inflammation. Thus, an efficient inhibitor targeting VEGFRs could be useful in suppressing various diseases.
\end{abstract}

ngiogenesis, blood vessel formation, is esAsential for supplying oxygen and nutrients to the tissues and for removing carbon dioxide and waste materials (Hanahan and Folkman 1996; Risau 1997). Furthermore, lymph vessels are crucial for the absorption of tissue fluids and the recovery of tissue-infiltrated lymphocytes. In the 1980s, two proteins, vascular permeability factor (VPF) and vascular endothelial growth factor receptors (VEGF), were independently isolated. However, in 1989, these proteins were found to be identical and encoded by a single gene (Ferrara and DavisSmith 1997; Dvorak 2002). This protein, named
VEGF (or VEGF-A), has a homodimeric structure with three intramolecular and two intermolecular disulfide $(\mathrm{S}-\mathrm{S})$ bonds. However, its receptor and signaling patterns were yet to be elucidated.

In 1990, we isolated from human placenta a novel receptor-type tyrosine kinase (RTK) cDNA encoding a protein with seven Ig-like domains in its extracellular region. We designated it Flt-1 (Fms-like tyrosine kinase-1; the first type-V RTK) because of its similarity with the Fms (M-CSFR) and PDGFR family (Fig. 1) (Shibuya et al. 1990; Shibuya 1995). On the basis of this similarity, the ligand of Flt-1 was

Editors: Joseph Schlessinger and Mark A. Lemmon

Additional Perspectives on Signaling by Receptor Tyrosine Kinases available at www.cshperspectives.org

Copyright (C) 2013 Cold Spring Harbor Laboratory Press; all rights reserved; doi: 10.1101/cshperspect.a009092

Cite this article as Cold Spring Harb Perspect Biol 2013;5:a009092 
M. Shibuya

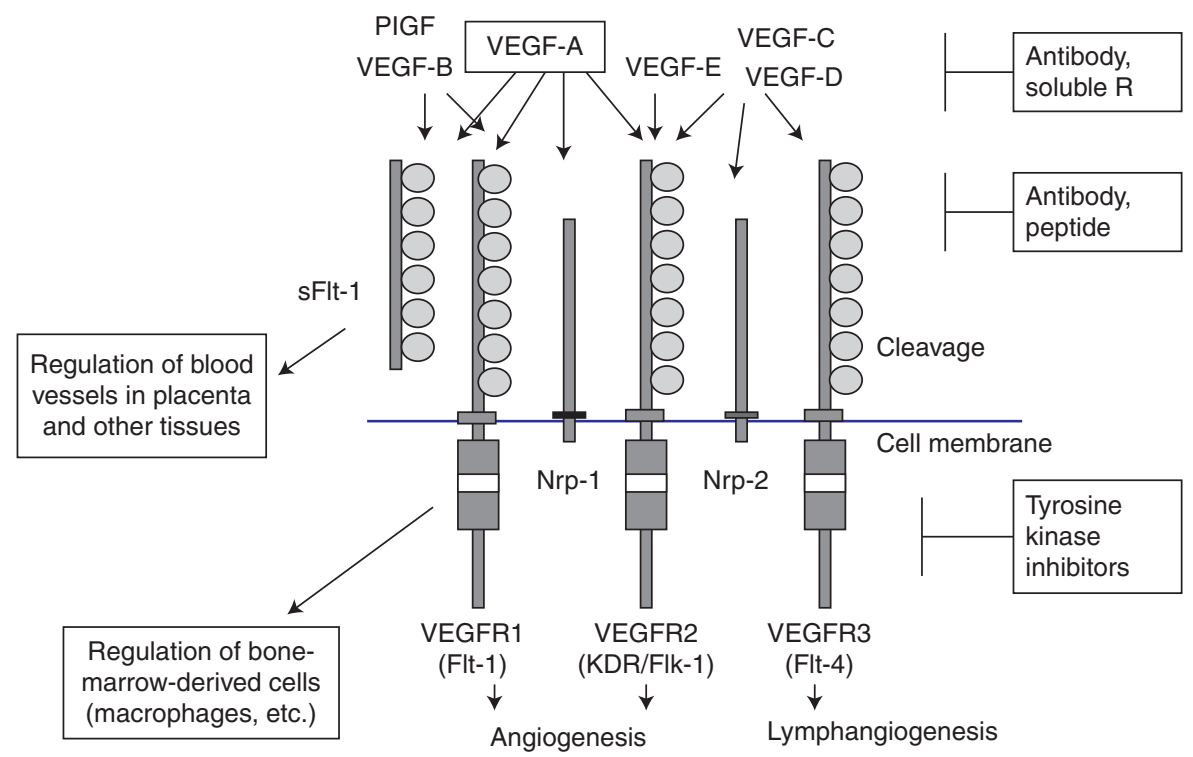

Figure 1. The VEGF-VEGFR system and its inhibitors. VEGF (VEGF-A) and its receptors, VEGFR1 and VEGFR2, play a major role in vasculogenesis and angiogenesis. VEGFR3 regulates not only lymphangiogenesis but also angiogenesis under pathological conditions. Neuropilins (Nrp)-1 and Nrp-2 function as coreceptors for VEGFR1 and VEGFR2, respectively, and efficiently stimulate VEGFR signaling. A heterodimer formed between two receptors, such as VEGFR1/VEGFR2 and VEGFR2/VEGFR3, was reported to regulate angiogenesis as well as lymphangiogenesis. Various inhibitors were developed to suppress this system, and some of them are now widely used clinically.

suggested to be a protein with a homodimeric structure, such as M-CSF and PDGF. In 1992, De Vries et al. (1992) reported tight binding and activation of Flt-1 with VEGF, indicating that Flt-1 is the first receptor for VEGF (VEGFR1).

Several years later, two RTKs structurally related to Flt-1 were isolated: one was KDR/ Flk-1 (kinase-insert [KI] domain receptor in humans/fetal liver kinase-1 in mice; VEGFR2), while the other was Flt-4 (VEGFR3) (Matthews et al. 1991; Terman et al. 1991; Alitalo and Carmeliet 2002). VEGF binds VEGFR1 and VEGFR2, but not VEGFR3. Other VEGF family members, VEGF-C and VEGF-D, bind VEGFR3 and activate it for lymphangiogenesis (Joukov et al. 1997; Achen et al. 1998).

When we isolated full-length flt-1 cDNA, we also found a short 3-kb-long flt-1 mRNA, encoding a peptide without a TK domain that was highly expressed in normal placenta (Shibuya et al. 1990). This short flt-1 mRNA was later reported to encode a soluble Flt-1 (sFlt-1) pro- tein without trans-membrane (TM) and TK domains (Kendall and Thomas 1993; Hornig et al. 2000; Helske et al. 2001). Soluble Flt-1 is strongly expressed in the placental trophoblasts and is abnormally expressed in preeclampsia (Koga et al. 2003; Maynard et al. 2003). The main function of sFlt-1 is considered to be trapping of endogenous VEGF. Thus, extreme trapping and suppression of VEGF in various tissues of the body may result in the hypertension and proteinuria observed in preeclampsia patients (Levine et al. 2004).

VEGF heterozygotic knockout mice (VEG $F-A^{+/-}$mice) are embryonic lethal because of immature development of angiogenesis, indicating that the concentration of VEGF is tightly regulated in tissues during embryogenesis (Carmeliet et al. 1996; Ferrara et al. 1996). The VEGF-VEGFR system is the major regulator of angiogenesis. Therefore, this system is an attractive target for antiangiogenic therapy and proangiogenic therapy. 


\section{STRUCTURAL CHARACTERISTICS OF VEGFRs AND THEIR RELATIONSHIP WITH OTHER RTKs}

Mammals possess three VEGFR genes, namely, VEGFR1, VEGFR2, and VEGFR3, which produce four proteins, namely, VEGFR1, VEGFR2, VEGFR3, and sFlt-1 (sVEGFR1) (Shibuya and Claesson-Welsh 2006). The three receptors have 7 Ig-like domains that, except for the fourth Iglike domain, possibly form $\mathrm{S}-\mathrm{S}$ bonds. Unlike the other domains, the fourth domain does not have cysteines, suggesting that its tertiary structure is different from the others (Shibuya et al. 1990). In addition, the extracellular region of VEGFR3 is cleaved by a protease at the fifth Ig domain, and the amino-terminal and carboxyterminal peptides are fixed with an $\mathrm{S}-\mathrm{S}$ bond in the functional receptor (Alitalo and Carmeliet 2002).

The overall structure of the first to fifth Ig domains in VEGFRs is very similar to the extracellular region of the M-CSFR/PDGFR family, the type-III RTKs. The region spanning from the second to third Ig regions of M-CSFR/ PDGFRs is the ligand-binding site. Similarly, the same regions in VEGFRs contain the binding regions for VEGF and VEGF-family members (Keyt et al. 1996; Tanaka et al. 1997; Shinkai et al. 1998). For the ligand-dependent activation of VEGFRs, Yang et al. (2010) recently reported that a direct interaction between the extracellular domains of two receptors is required.

VEGFR1: Dual Roles in Angiogenesis and the Antiangiogenic Effect of the Ligand-Binding Domain

VEGFR1 binds VEGF at a very high affinity of $K_{d}=1-10$ pmol, and binds two other members of the VEGF family, namely, placental growth factor (PlGF) and VEGF-B (Sawano et al. 1996; Ferrara 2004; Shibuya and Claesson-Welsh 2006). Mice deficient in flt-1 (flt-1 $1^{-/}$mice) die at embryonic day (E) 8.0-8.5 because of overgrowth and disorganization of blood vessels (Fong et al. 1995). This phenotype suggests that VEGFR1 plays a negative role in angiogenesis during early embryogenesis and that it is needed to maintain an appropriate balance between the positive and negative regulators.

Because the affinity of VEGFR1 for VEGF is very high, the negative role of VEGFR1 suggests two possibilities: the ligand-binding region of VEGFR1 may trap VEGF, or TK activation in VEGFR1 may transduce a negative signal. To distinguish these possibilities, we generated TK domain-deficient mice ( flt-1 $\mathrm{TK}^{-/-}$ mice) by a knockout procedure. To our surprise, flt $-1 \mathrm{TK}^{-/-}$mice were healthy, and angiogenesis was normal in the embryos (Fig. 2) (Hiratsuka et al. 1998). These results clearly indicate that the negative role of VEGFR1 in angiogenesis is localized to the ligand-binding domain of the receptor, and it, most likely, involves trapping VEGF and decreasing its concentration around vascular endothelial cells (EC). In flt-1 $\mathrm{TK}^{-/-}$mice, VEGF-dependent migration of macrophages was deficient, supporting the idea that VEGFR1 also generates a positive signal, for example, one that stimulates cell migration (Barleon et al. 1996; Clauss et al. 1996; Hiratsuka et al. 1998; LeCouter et al. 2003).

Additional studies addressed whether the ligand-binding region of VEGFR1 needed to be localized on the membrane of vascular endothelial cells (ECs) in order to play a negative role in angiogenesis. To clarify this, knockout mice were generated in which the TM domain as well as the TK domain of VEGFR1 was missing (flt-1 TM-TK ${ }^{-/-}$mice). In the mutant mice, approximately half the littermates were embryonic lethal, but the other half were healthy, similar to the flt-1 $\mathrm{TK}^{-/-}$mice (Hiratsuka et al. 2005). Therefore, these results suggest that the ligand-binding region of VEGFR1 should be fixed on the cell membrane to function appropriately as a negative regulator of angiogenesis. If the TM domain is missing, the mortality of the embryo may depend on the location of the solubilized VEGFR1. When the peptide is mostly localized near the membrane of vascular ECs, it works properly as a negative regulator just as in $\mathrm{flt}-1 \mathrm{TK}^{-/}$mice; however, when it is localized far from the membrane, its regulatory activity does not work properly, resulting in disorganization of blood vessels and embryonic lethality. 
M. Shibuya
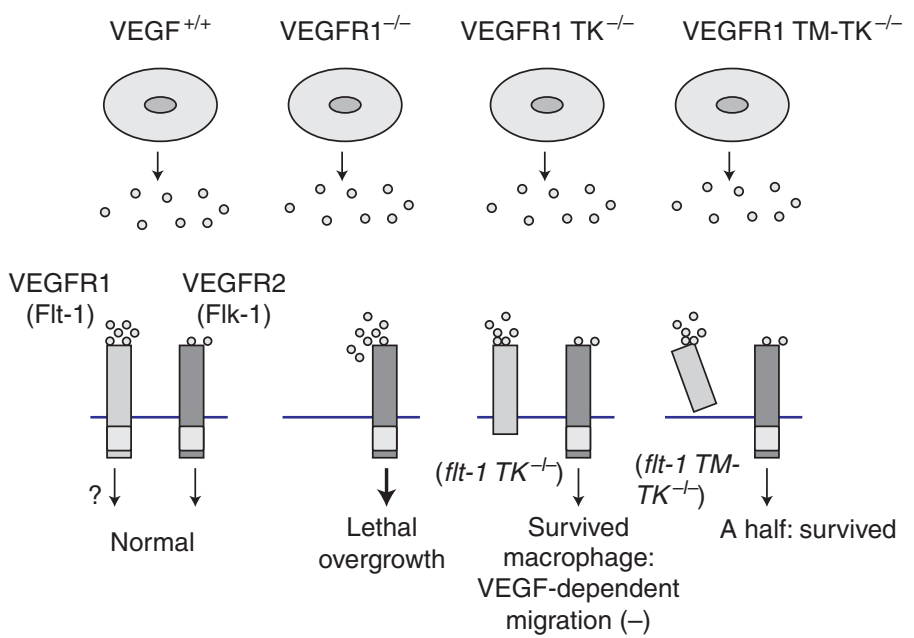

Figure 2. VEGFR1 has dual roles, positive and negative, in angiogenesis. VEGFR1 has a strong binding affinity for VEGF, but its kinase activity is much weaker than that of VEGFR2. VEGFR1 knockout mice (i.e., flt-1 ${ }^{-/-}$ mice) die during early embryogenesis because of overgrowth of angiogenesis, indicating a negative role for VEGFR1 in angiogenesis. VEGFR1-signal-deficient mice (i.e., flt-1 $\mathrm{TK}^{-9-}$ mice), organize blood vessel structure in a normal manner. Thus, the negative function of VEGFR1 localizes to the ligand-binding domain. flt-1 $T M-T K^{-/-}$mice indicate that about half of littermates are healthy but the other half are embryonic lethal due to poor development of blood vessels.

\section{VEGFR2: The Major Positive Signal Transducer} for Angiogenesis

$V E G F^{+/-}$heterozygous mice die at the embryonic stage because of insufficient organization of blood vessel formation. Instances of haploid insufficiency like VEGF gene are very rare in mammals, indicating that the degree of positive signal from the VEGF-VEGFR system is tightly regulated in the body.

VEGFR2 is the second high-affinity receptor for VEGF: its binding affinity is about onetenth that of VEGFR1. However, the TK activity of VEGFR2 is about 10-fold stronger than the TK activity of VEGFR1, suggesting that VEGFR2 is the major signal transducer for angiogenesis. Mice deficient in VEGFR2 ( $f l k-$ $1^{-/-}$mice) were embryonic lethal at E8.5, because of lack of vasculogenesis/angiogenesis, indicating that VEGFR2 is the main positive signal transducer for blood vessel formation in embryogenesis (Shalaby et al. 1995).

VEGFR1 and VEGFR2 are highly homologous at the amino acid level. Particularly, tyrosine residues in the carboxy-terminal region are well conserved: Y1175 in VEGFR2 and Y1169 in
VEGFR1 are part of similar amino acid motifs (Shibuya 1995), and appear to be crucial for downstream signaling, as discussed below.

VEGFR3: Regulator of Both Lymph Vessel and Blood Vessel Formation

VEGFR3 is expressed in lymph ECs as well as in venous ECs during early embryogenesis. VEGFR3 binds VEGF-C and VEGF-D (Alitalo and Carmeliet 2002; Lohela et al. 2009). These ligands are synthesized in precursor forms that have limited affinity for the receptor. However, after processing in both amino- and carboxy-terminal portions, the mature ligands bind VEGFR3 with a higher affinity (Joukov et al. 1997; McColl et al. 2007). In addition, mature VEGF-C and VEGF-D bind VEGFR2 at a lower affinity and can activate the receptor. Although VEGF-C and VEGF-D can activate both VEGFR3 and VEGFR2, a mutant of VEGF-C, VEGF-C156S, which binds and activates only VEGFR3, stimulates lymphangiogenesis equally well as wildtype VEGF-C does in the keratin-promoterdriven transgenic mouse system (Veikkola et 
al. 2001). This suggests that the activation of VEGFR3 is sufficient for signaling toward lymphangiogenesis.

VEGFR3 knockout mice ( $f l t-4^{-/}$mice) die because of disorganization of blood vessels at E9.5 when lymphangiogenesis has not yet occurred (Dumont et al. 1998). These results clearly show that VEGFR3 plays an important role not only in lymphangiogenesis but also in blood vessel formation before lymphangiogenesis during early embryogenesis.

Structurally, VEGFR3 is slightly less homologous to VEGFR1 and VEGFR2 than the latter two receptors are to each other. Consequently, VEGFR3 differs from VEGFR1 and VEGFR2 in at least two ways. First, the extracellular domain in VEGFR3 is cleaved and fixed with a $\mathrm{S}-\mathrm{S}$ bond, whereas the extracellular domains in VEGFR1 and VEGFR2 are not cleaved. Second, in the carboxy-terminal sequences, a tyrosine residue critical for signaling, Y1175 in VEGFR2 and Y1169 in VEGFR1, is not conserved in VEGFR3, suggesting a difference in signaling (Shibuya and Claesson-Welsh 2006).

Makinen et al. (2001) reported that VEGFR3 uses PKC and Ras pathways for lymphangiogenesis. Furthermore, most familial lymphedema patients were found to carry various mutations in the VEGFR3 gene, particularly in the tyrosine kinase domain. These mutations cause a decrease in kinase activity and signaling, indicating that proper lymphangiogenesis in humans is dependent on the TK activity of VEGFR3 (Irrthum et al. 2000; Karkkainen et al. 2001).

sFlt-1: A Powerful Endogenous Antiangiogenic Protein

sFlt-1 (sVEGFR-1) consists of six Ig-like domains and a 31-amino-acid-long tail (Kendall and Thomas 1993; Shibuya 2011). The sFlt-1 mRNA is generated by premature termination within intron 13. Surprisingly, the tail sequence encoded in the $5^{\prime}$ portion of intron 13 is structurally highly conserved among vertebrates. We found that chicken sFlt- 1 and mouse sFlt- 1 also have the 31-amino-acid-long tail. The tails of humans, mice, and chickens are highly homologous to each other, approximately $74 \%$ iden- tical at the amino acid level (Kondo et al. 1998; Yamaguchi et al. 2002). This significant homology strongly suggests that the tail sequence has biological significance, and that full-length exon 13 in the VEGFR1 gene encodes a long form of the peptide that includes the 31-aminoacid-long portion.

Amphibians, but not fish, have mRNA for sFlt-1. Therefore, the system of three VEGFRs and one sFlt-1 was established at an early stage of development in vertebrates (i.e., the amphibian stage). Because sFlt-1 can trap the major angiogenic factor VEGF, it suggests that sFlt-1 is an important suppressor of angiogenesis in various animal tissues.

Furthermore, sFlt-1 might have been a key player in the establishment of the placenta-carrying animals (i.e., mammals). The placenta is essential for communication between the fetal and maternal circulatory systems. Oxygen and nutrients are supplied from the maternal circulation to the fetal circulation, whereas wasted materials are transferred from the fetal circulation to the maternal circulation. Under physiological conditions, sFlt-1 is highly expressed in trophoblasts, which are located between the maternal and fetal blood vessels in the placenta (Helske et al. 2001). Angiogenesis on both fetal and maternal sides in this tissue must be well organized, without overgrowth of blood vessels, to avoid fusion or abnormal hyperpermeability. To obtain such a tight regulation of angiogenesis, sFlt-1, a strong endogenous inhibitor of VEGF, is considered a very efficient molecule. Therefore, it seems reasonable that sFlt-1 plays an important role in the suppression of abnormal angiogenesis in placenta to maintain its function (Clark et al. 1998; Shibuya 2011).

Shorter forms of sFlt-1 that contain only the first three, four, or five Ig domains still maintain a high affinity for VEGF (Tanaka et al. 1997). In contrast, short peptides of VEGFR2, with only the first four or five Ig domains, have a lower affinity for VEGF, 10- to 50-fold lower than fulllength VEGFR2 (Shinkai et al. 1998). Recently, Albuquerque et al. (2009) reported that the VEGFR2 gene also produces sVEGFR2. When sVEGFR2 has six Ig domains, it could bind VEGF or VEGF-C. However, when it is cleaved 
M. Shibuya

to less than six Ig domains, it might be difficult to regulate VEGF/VEGF-C levels because of its weaker ligand-trapping activity.

\section{An Intimate Relationship of sFlt-1 with Preeclampsia}

In 2003, Koga et al. (2003) and Maynard et al. (2003) reported that sFlt-1 is abnormally high in the serum of preeclampsia patients. Furthermore, Levine et al. (2004) showed a tight relationship between the degree of preeclampsia and the level of sFlt- 1 in serum, strongly suggesting that sFlt-1 is an important cause of preeclampsia symptoms such as hypertension and proteinuria. Using a pregnant rat model, Maynard et al. (2003) showed that artificial introduction of sFlt-1 using vector system-induced preeclampsia-like symptoms, specifically hypertension and proteinuria. The molecular mechanism for the overexpression of sFlt- 1 in the trophoblasts of preeclampsia patients is not yet fully understood. However, a similar phenomenon was observed with antiangiogenic therapy in the treatment of cancer patients with VEGFtrapping antibody (bevacizumab)-induced adverse effects, including hypertension and proteinuria, which are symptoms observed in preeclampsia (Hurwitz et al. 2004). Therefore, sFlt-1 is an attractive target for future efforts to suppress the symptoms of preeclampsia and improve overall conditions for both mother and baby (Fig. 3) (Thadhani et al. 2011).

Soluble Flt-1 is expressed not only in trophoblasts but also in other cell types, including corneal epithelial cells. Ambati et al. (2006) showed that sFlt-1 expressed in the cornea is important for maintaining the avascularity of the lens and transparent vision.

\section{SIGNAL TRANSDUCTION OF VEGFR: A UNIQUE DEPENDENCY ON THE PLC- $\gamma$ - PKC PATHWAY}

\section{A New Function of sFlt-1 in Kidney}

Recently, sFlt-1 has been shown to have another interesting role in vivo. Quaggin's group demonstrated that the podocytes in the glomeruli in

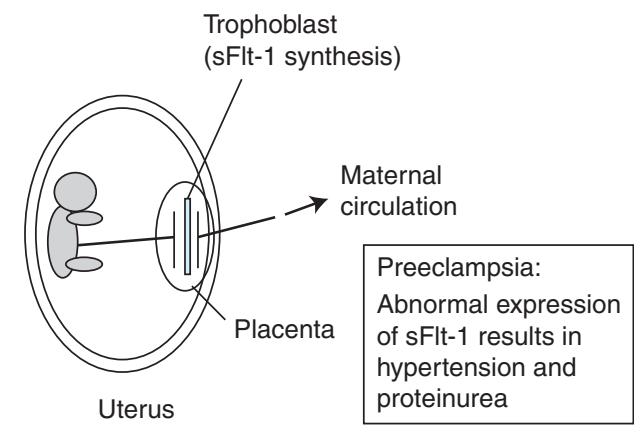

Figure 3. sFlt-1: An endogenous VEGF-inhibitor intimately related to preeclampsia. The soluble form of VEGFR1, sFlt-1, is expressed in normal placenta, particularly in the trophoblasts. Expression of the sFlt-1 gene is abnormally increased in preeclampsia patients, and the excess sFlt-1 is distributed via the bloodstream to various maternal tissues. sFlt-1 traps endogenous VEGF, resulting in hypertension and proteinuria.

kidney secrete sFlt-1 to regulate glomerular barrier function, and knockdown of sFlt-1 in the podocytes results in chronic proteinurea, similar to the cases of patients with nephrotic syndrome (Jin et al. 2012).

In the 5 Ig-RTKs, such as M-CSFR and PDG FRs, the 60-amino-acid-kinase-insert (KI) sequence located in the middle of the TK domain has several conserved tyrosine residues with YMXM or YXXM motifs. Once phosphorylated at the tyrosine residue, these motifs become strong binding and activation sites for PI3 kinase (PI3K), resulting in the activation of the PI3KRas-MAPK pathway for cell proliferation and transformation (Heldin and Westermark 1999). However, interestingly, none of the VEGFRs contains the YXXM motif in their KI regions. Even after activation with VEGF, VEGFR1 and VEGFR2 barely bind the PI3K subunit p85. These differences strongly suggest that the major signaling pathway of VEGF-VEGFR is different from that of M-CSFR/PDGFRs.

Our study and previous studies have found that PKCs, particularly PKC- $\beta$, play an important role in VEGFR2 signaling (Xia et al. 1996; Takahashi and Shibuya 1997; Takahashi et al. 1999). After stimulation with VEGF, several tyrosines, including Y1175 and Y1214, were 
VEGFR Activation and Signaling

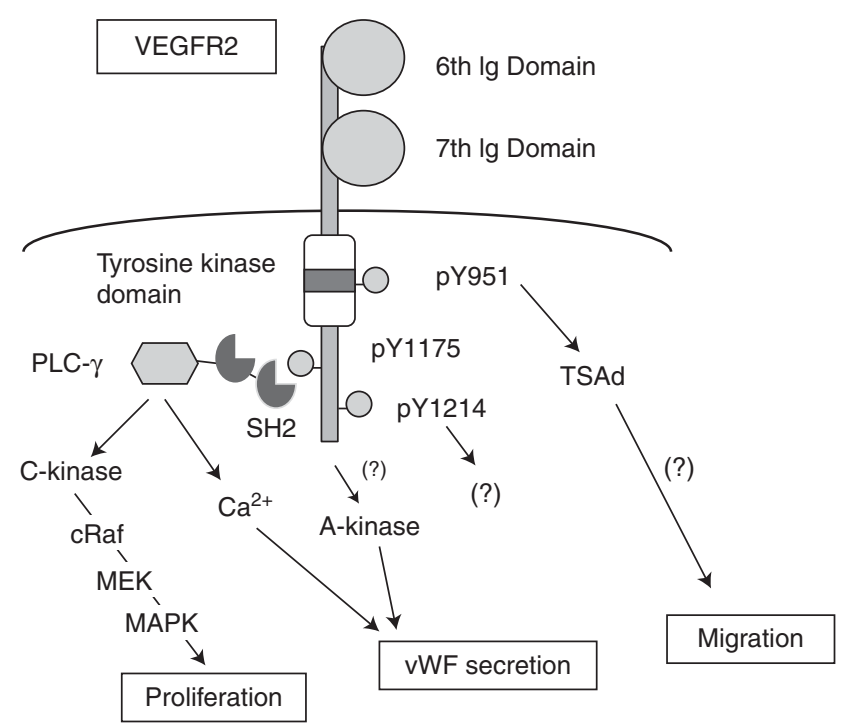

Figure 4. A unique signaling pathway from VEGFR2 toward angiogenesis. The Y1175 site is one of the major autophosphorylation sites on VEGFR2 after stimulation with VEGF. The pY1175-containing motif is the binding and activation site for PLC- $\gamma$. It stimulates PKC-Raf-MEK-MAPK and calcium mobilization pathways for EC activation and proliferation.

strongly phosphorylated. We found that phosphorylated Y1175 (pY1175), but not pY1214, is the critical binding site for the carboxy-terminal SH2 domain of PLC- $\gamma$ and the initiation site of the PLC- $\gamma$-PKC-Raf-MEK-MAPK pathway for the proliferation of ECs (Fig. 4) (Takahashi et al. 2001). In addition, activation of PLC- $\gamma$ stimulates $\mathrm{Ca}^{2+}$ mobilization within the cell. Replacement of Y1175 with phenylalanine in VEGFR-2 or intracellular injection of pY1175blocking antibody (anti-pY1175 peptide Ab) significantly inhibits the activation of the PLC- $\gamma$ PKC-MAPK pathway, suppressing the cell proliferation signal in vitro.

To examine whether pY1175 in VEGFR2 is crucial for the angiogenic signal in vivo, we generated a knock-in mouse with a point mutation at amino acid 1175 (1173 in mice) that changes tyrosine to phenylalanine (F). Homozygotic Y1173F/F mice, but not Y1212F/F mice, die because of lack of vasculogenesis similar to $f l k-1^{-/-}$mice, even though Y1173F/F mice still express VEGFR2 with other phosphotyrosine sites (Sakurai et al. 2005). These results support the idea that signaling from pY1173 of VEGFR2 to the PLC- $\gamma$-PKC-MAPK pathway is essential for vasculogenesis in embryogenesis. Interestingly, Sase et al. (2009), using a murine embryonic stem (ES) cell system, reported that differentiation of ECs from ES cells strongly depends on the VEGFR2-pY1173 to PLC- $\gamma$ pathway. Furthermore, a spontaneous mutant of the $P L C-\gamma 1$ gene in zebrafish is lethal because of deficiency of arteriogenesis (Lawson et al. 2003). These findings strongly suggest that the VEGFR-PLC$\gamma$-PKC-MAPK pathway is essential for angiogenic signals, not only in mammals but also in fish, the earliest vertebrates.

Recently, Wang et al. (2008) reported that the VEGFR2-PLC- $\gamma$-PKC pathway activates the protein kinase $\mathrm{D}(\mathrm{PKD})$-histone-deacetylase 7 (HDAC7) pathway for gene expression toward EC proliferation and migration. In addition, Xiong et al. (2009) found that VEGFR2-pY1175 is essential for the release of von Willebrand factor (vWF) from the ECs to regulate the coagulation system.

VEGF stimulates not only proliferation but also sprouting, survival, migration, and tube formation of ECs. Phosphorylated Y951 was reported to be important for cell migration via recruitment of T-cell-specific adaptor protein 
M. Shibuya

(TSAd) (Matsumoto et al. 2005). Survival signals appear to be generated from the PKCMAPK pathway and the PI3K pathway. However, the phosphotyrosine(s) on VEGFR2 that is the activation site for PI3K has not yet been identified.

VEGFR1 is expressed not only on vascular ECs but also on macrophages, trophoblasts, tumor cells, and others (Wu et al. 2006; Tsuchida et al. 2008). VEGFR1 is involved in the survival, angiogenic signaling (albeit not strong), and migration of ECs and macrophages (Sawano et al. 2001; LeCouter et al. 2003). VEGFR1 is also involved in bone marrow reconstitution (Niida et al. 2005), and it stimulates tumor growth, metastasis, and inflammation (Hiratsuka et al. 2002; Kaplan et al. 2005; Murakami et al. 2006; Kerber et al. 2008; Muramatsu et al. 2010). However, the signaling of VEGFR1 to promote cell migration has not yet been characterized. Using a stable VEGFR1 overexpressing human EC line, we recently examined this signaling. An intracellular scaffold protein, receptor of activated protein kinase C1 (RACK1), was involved in the migration signal, and stimulated the PI3K-Akt-Rac1 pathway (Wang et al. 2011).

\section{CROSS TALK BETWEEN VEGF-VEGFR SIGNAL AND OTHER SIGNALING PATHWAYS}

The VEGF-VEGFR system is reported to communicate with a variety of other signaling systems. In angiogenesis, upon stimulation with VEGF, capillary ECs can shift to two major types, namely, tip cells and stalk cells (Ruhrberg et al. 2002 ). A tip cell has many filopodia at its front for migration and has low cell proliferation activity. On the other hand, a stalk cell forms a tubular structure and has high proliferation activity. In this system, tip cells express Dll4, a ligand of the Delta family, and bind and activate Notch receptors on stalk cells. Notch signaling in stalk cells suppresses the expression of VEGFR2 to an appropriate level, thereby stimulating cell proliferation (Jakobsson et al. 2009). In addition, sFlt- 1 expression in stalk cells regulates tip cell formation in angiogenesis (Chappell et al. 2009).
Recently, Stefater et al. (2011) reported that the Wnt signal cooperates with sFlt-1 to regulate retinal blood vessel formation in perinatal development. The Ang/Tie system is another important regulator of angiogenesis. Ang2, in the presence of VEGF, promotes angiogenesis. However, without VEGF, Ang2 suppresses angiogenesis because of induction of vascular instability. The relationship between the Ang/Tie system and the VEGF/VEGFR system appears to be context dependent, and is yet to be fully understood.

\section{PHYLOGENETIC DEVELOPMENT OF VEGFRS}

Genes encoding type-V RTKs (7 Ig-RTKs) have already been identified in nonvertebrates. Examples include the Drosophila DVR/PVR gene and the sea squirt VEGFR-like receptor gene. Except for Caenorhabditis elegans, which possesses three genes encoding type-V RTKs, other nonvertebrates have only one type-V RTK gene. Because nonvertebrates do not have any type-III RTK (5 Ig-RTK) genes, the type-V RTK gene is considered the ancestor of genes in the VEGFR (7 Ig-RTKs) and PDGFR (5 Ig-RTKs) families, including M-CSFR, CSFR, and Flt3 in mammals and other vertebrates. Based on the structural homology, both cis gene duplication and trans gene duplication may have occurred twice for each during the early development of vertebrates (Fig. 5) (Shibuya 2002). Drosophila DVR is mainly used for cell migration and not for cell proliferation (Duchek et al. 2001), and its signaling uses JNK and other pathways (Ishimaru et al. 2004). The exon-intron structure for the KI in VEGFRs differs from that in the PDGFR family (Kondo et al. 1998), suggesting that the $\mathrm{KI}$ sequence was replaced during the generation of the 5 Ig-RTKs (PDGFRs) from the 7 Ig-RTKs. During this step, the KI of the 5 Ig-RTKs may have acquired the YXXM motifs that produce strong cell proliferation signals.

\section{ANTIANGIOGENIC THERAPY TARGETING THE VEGF-VEGFR SYSTEM}

Solid tumors secrete a variety of angiogenic factors, such as VEGF, fibroblast growth factor 


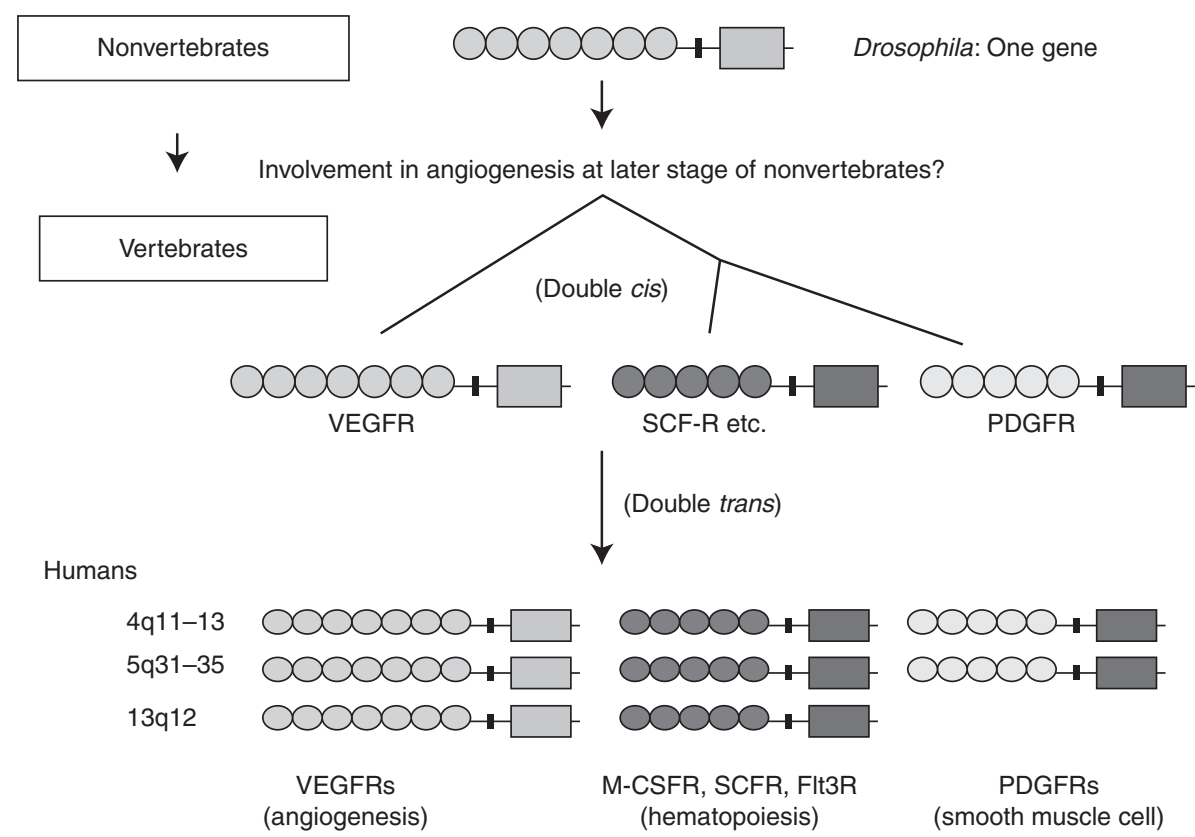

Figure 5. Phylogenetic development of the 7 Ig-RTKs (VEGFRs) and the 5 Ig-RTKs: A hypothesis. Most nonvertebrates carry a single 7 Ig-RTK gene. Double cis gene duplication followed by double trans gene duplication appears to have generated the $7 \mathrm{Ig}$-RTK and $5 \mathrm{Ig}$-RTK supergene families in vertebrates.

(FGF), hepatocyte growth factor (HGF), and PDGF. However, among these factors, VEGF is thought to play a central role in tumor angiogenesis because blocking VEGF using either anti-VEGF neutralizing antibody or sFlt-1 protein efficiently suppresses solid tumor growth in mouse models (Kim et al. 1993). On the basis of these findings, Genentech Co. developed a human VEGF-neutralizing antibody (bevacizumab, Avastin) for cancer treatment. In 2003, phase III studies of colorectal cancer clearly showed that a combination of chemotherapy with bevacizumab extended overall survival (OS) from 15.6 months (control group; without bevacizumab) to 20.3 months (group with bevacizumab) (Hurwitz et al. 2004). Now, in 2011, this anti-VEGF antibody is approved for use in treating colorectal cancer, lung cancer (nonSCLC) (Cohen et al. 2007), and glioblastoma in many countries. For breast cancer patients, the Food and Drug Administration (FDA) in the United States approved the use of bevacizumab in 2005. However, after reevaluating a recent clinical study, in 2010, the FDA withdrew its approval, because bevacizumab was less efficacious in improving OS in patients. On the other hand, in 2011, bevacizumab was approved for the treatment of breast cancer patients in several countries because it improved progression-free survival (PFS). Additional clinical studies are necessary to clarify the efficacy of anti-VEGF molecules in various tumors at different settings.

Several chemicals, such as sorafenib and sunitinib, which act as inhibitors of multiple tyrosine kinases, including VEGFRs, were developed; these have been widely used to treat renal cell cancer and hepatocellular cancer because of the increase in the OS.

Several mechanisms have been proposed to explain the efficacy of VEGF-VEGFR inhibitors. These include suppression of preexisting tumor vasculature, suppression of new angiogenesis, and vascular normalization in tumor tissues. Vascular normalization may decrease the abnormal vascular permeability of tumor vessels, resulting in normalized intratumoral pressure and better distribution of anticancer chemicals (Jain 2005). 
M. Shibuya

Although more than five types of solid tumors are sensitive to anti-VEGF-VEGFR medicines, refractoriness or acquired resistance to these drugs might occur after long-term treatment. Expression of other angiogenic factors or receptors such as c-Met after anti-VEGFVEGFR therapy was reported (You et al. 2011). Furthermore, tumors might acquire a phenotype resistant to conditions of lower availability of oxygen and nutrients through metabolic changes and increases in the phospho-Akt levels (Osawa et al. 2009). The various responses of tumor tissues to antiangiogenic therapy should be clarified to aid the development of more efficient drugs that can improve overall and progression-free survival.

\section{PROANGIOGENIC THERAPY USING THE VEGF-VEGFR SYSTEM}

Ischemic diseases, such as cardiac infarction and brain stroke, are major mortal diseases in humans. Because the VEGF-VEGFR system plays a central role in angiogenesis in mammals, VEGF-A is an important candidate for therapeutic angiogenesis. However, a transgenic mouse model using keratin-promoter-driven VEGFA induced angiogenesis with inflammatory responses. Kunstfeld et al. (2004) and others reported that the skin tissue in VEGF-A transgenic mice showed severe inflammation with hyperpermeability and lymphangiogenesis, and could be a model for dermal psoriasis. VEGF binds not only VEGFR2 but also VEGFR1. The activated VEGFR1 on macrophages stimulates cell migration as well as the production of inflammatory cytokines and lymphangiogenic factors like VEGF-C. We and others found that an Orf-virus-genome encoded a VEGF-like molecule (i.e., VEGF-E), which binds and activates only VEGFR2, not VEGFR1 (Lyttle et al. 1994; Ogawa et al. 1998). This characteristic of VEGF-E could promote angiogenesis without stimulating inflammation. We showed that K14-VEGF-E transgenic mice have increased angiogenesis under the skin without an inflammatory response (Kiba et al. 2003a). In these mice, vascular permeability was in the normal range, and inflammatory cytokines such as IL-6 and tumor necrosis factor (TNF) were not significantly induced. Thus, the VEGFR2-specific ligand VEGF-E appears be a good candidate for proangiogenic therapy. A possible adverse effect of this molecule might be antigenicity because the VEGF-E gene is not present in the human genome. To avoid the antigenicity of VEGF-E, we generated a chimeric molecule consisting of VEGF-E and a human protein, PlGF, that maintains VEGFR2-stimulating activity with less antigenicity (Kiba et al. 2003b; Zheng et al. 2006). Humanized VEGF-E, the Ang1-related protein COMP-Ang1 (Cho et al. 2005), FGF, and HGF (Azuma et al. 2006) are hopeful candidates for the treatment of ischemic diseases.

\section{CONCLUSION}

VEGFRs have a 7 Ig-RTK structure and activate a unique signaling pathway for angiogenesis and lymphangiogenesis. Soluble Flt-1 (sFlt-1/ sVEGFR-1), a gene product of VEGFR-1, is a strong endogenous VEGF inhibitor, tightly linked with the onset of preeclampsia symptoms. The VEGF-VEGFR system is deeply involved in various diseases, including cancer and ischemic diseases. Thus, further analysis of this system may provide important clinical strategies.

\section{ACKNOWLEDGMENTS}

This work is supported by Grant-in-Aid Special Project Research on Cancer-Bioscience 17014020 from the Ministry of Education, Culture, Sports, Science and Technology of Japan.

\section{REFERENCES}

Achen MG, Jeltsch M, Kukk E, Mäkinen T, Vitali A, Wilks AF, Alitalo K, Stacker SA. 1998. Vascular endothelial growth factor D (VEGF-D) is a ligand for the tyrosine kinases VEGF receptor 2 (Flk1) and VEGF receptor 3 (Flt4). Proc Natl Acad Sci 95: 548-553.

Albuquerque RJ, Hayashi T, Cho WG, Kleinman ME, Dridi S, Takeda A, Baffi JZ, Yamada K, Kaneko H, Green MG, et al. 2009. Alternatively spliced vascular endothelial growth factor receptor-2 is an essential endogenous inhibitor of lymphatic vessel growth. Nat Med 15: 1023-1030.

Alitalo K, Carmeliet P. 2002. Molecular mechanisms of lymphangiogenesis in health and disease. Cancer Cell 1: 219-227. 
Ambati BK, Nozaki M, Singh N, Takeda A, Jani PD, Suthar T, Albuquerque RJ, Richter E, Sakurai E, Newcomb MT, et al. 2006. Corneal avascularity is due to soluble VEGF receptor-1. Nature 443: 993-997.

Azuma J, Taniyama Y, Takeya Y, Iekushi K, Aoki M, Dosaka N, Matsumoto K, Nakamura T, Ogihara T, Morishita R. 2006. Angiogenic and antifibrotic actions of hepatocyte growth factor improve cardiac dysfunction in porcine ischemic cardiomyopathy. Gene Ther 13: 1206-1213.

Barleon B, Sozzani S, Zhou D, Weich HA, Martovani A, Marme D. 1996. Migration of human monocytes in response to vascular endothelilal growth factor (VEGF) is mediated via the VEGF receptor flt-1. Blood 87: 33363343.

Carmeliet P, Ferreira V, Breier G, Pollefeyt S, Kleckens L, Gertsenstein M, Fahrig M, Vandenhoeck A, Harpal K, Eberhardt C, et al. 1996. Abnormal blood vessel development and lethality in embryos lacking a single VEGF allele. Nature 380: 435-439.

Chappell JC, Taylor SM, Ferrara N, Bautch VL. 2009. Local guidance of emerging vessel sprouts requires soluble Flt-1. Dev Cell 17: 377-386.

Cho CH, Kim KE, Byun J, Jang HS, Kim DK, Baluk P, Baffert F, Lee GM, Mochizuki N, Kim J, et al. 2005. Long-term and sustained COMP-Ang1 induces long-lasting vascular enlargement and enhanced blood flow. Circ Res 97: 86-94.

Clark DE, Smith SK, He Y, Day KA, Licence DR, Corps AN, Lammoglia R, Charnock-Jones DS. 1998. A vascular endothelial growth factor antagonist is produced by the human placenta and released into the maternal circulation. Biol Reproduct 59: 1540-1548.

Clauss M, Weich H, Breier G, Knies U, Röckl W, Waltenberger J, Risau W. 1996. The vascular endothelial growth factor receptor Flt-1 madiates biological activities. J Biol Chem 271: 17629-17634.

Cohen MH, Gootenberg J, Keegan P, Pazdur R. 2007. FDA drug approval summary: Bevacizumab (Avastin) plus Carboplatin and Paclitaxel as first-line treatment of advanced/metastatic recurrent nonsquamous non-small cell lung cancer. Oncologist 12: 713-718.

De Vries C, Escobedo JA, Ueno H, Houck K, Ferrara N, Williams LT. 1992. The fms-like tyrosine kinase, a receptor for vascular endothelial growth factor. Science 255: 989-991.

Duchek P, Somogyi K, Jekely G, Beccari S, Rorth P. 2001. Guidance of cell migration by the Drosophila PDGF/ VEGF receptor. Cell 107: 17-26.

Dumont DJ, Jussila L, Taipale J, Lymboussaki A, Mustonen T, Pajusola K, Breitman M, Alitalo K. 1998. Cardiovascular failure in mouse embryos deficient in VEGF receptor3. Science 282: 946-949.

Dvorak HF. 2002. Vascular permeability factor/vascular endothelial growth factor: A critical cytokine in tumor angiogenesis and a potential target for diagnosis and therapy. J Clin Oncol 20: 4368-4380.

Ferrara N. 2004. Vascular endothelial growth factor: Basic science and clinical progress. Endocr Rev 25: 581-611.

Ferrara N, Davis-Smyth T. 1997. The biology of vascular endothelial growth factor. Endocrine Rev 18: 4-25.

Ferrara N, Carver-Moore K, Chen H, Dowd M, Lu L, O'Shea KS, Powell-Braxton L, Hillan KJ, Moore MW. 1996. Het- erozygous embryonic lethality induced by targeted inactivation of the VEGF gene. Nature 380: 439-442.

Fong GH, Rossant J, Gertsentein M, Breitman ML. 1995. Role of the Flt-1 receptor tyrosine kinase in regulating the assembly of vascular endothelium. Nature 376: 66-70.

Hanahan D, Folkman J. 1996. Patterns and emerging mechanisms of the angiogenic switch during tumorigenesis. Cell 86: 353-364.

Heldin CH, Westermark B. 1999. Mechanism of action and in vivo role of platelet-derived growth factor. Physiol Rev 79: $1283-1316$.

Helske S, Vuorela P, Carpen O, Hornig C, Weich H, Halmesmaki E. 2001. Expression of vascular endothelial growth factor receptors 1, 2 and 3 in placentas from normal and complicated pregnancies. Mol Hum Reprod 7: 205-210.

Hiratsuka S, Minowa O, Kuno J, Noda T, Shibuya M. 1998. Flt-1 lacking the tyrosine kinase domain is sufficient for normal development and angiogenesis in mice. Proc Natl Acad Sci 95: 9349-9354.

Hiratsuka S, Nakamura K, Iwai S, Murakami M, Itoh T, Kijima H, Shipley JM, Senior RM, Shibuya M, MS Mincho, et al. 2002. MMP9 induction by vascular endothelial growth factor receptor- 1 is involved in lung specific metastasis. Cancer Cell 2: 289-300.

Hiratsuka S, Nakao K, Nakamura K, Katsuki M, Maru Y, Shibuya M. 2005. Membrane-fixation of VRGFR1 ligand-binding domain is important for vasculogenesis/ angiogenesis in mice. Mol Cell Biol 25: 346-354.

Hornig C, Barleon B, Ahmad S, Vuorela P, Ahmed A, Weich HA. 2000. Release and complex formation of soluble VEGFR-1 from endothelial cells and biological fluids. Lab Invest 80: 443-454.

Hurwitz H, Fehrenbacher L, Novotny W, Cartwright T, Hainsworth J, Heim W, Berlin J, Baron A, Griffing S, Holmgren E, et al. 2004. Bevacizumab plus irinotecan, fluorouracil, and leucovorin for metastatic colorectal cancer. N Engl J Med 350: 2335-2342.

Irrthum A, Karkkainen MJ, Devriendt K, Alitalo K, Vikkula M. 2000. Congenital hereditary lymphedema caused by a mutation that inactivates VEGFR3 tyrosine kinase. Am J Hum Genet 67: 295-301.

Ishimaru S, Ueda R, Hinohara Y, Ohtani M, Hanafusa $\mathrm{H}$. 2004. PVR plays a critical role via JNK activation in thorax closure during Drosophila metamorphosis. EMBO J 23: 3984-3994.

Jain RK. 2005. Normalization of tumor vasculature: An emerging concept in antiangiogenic therapy. Science 307: $58-62$.

Jakobsson L, Bentley K, Gerhardt H. 2009. VEGFRs and Notch: A dynamic collaboration in vascular patterning. Biochem Soc Trans 37: 1233-1236.

Jin J, Sison K, Li C, Tian R, Wnuk M, Sung HK, Jeansson M, Zhang C, Tucholska M, Jones N, et al. 2012. Soluble FLT1 binds lipid microdomains in podocytes to control cell morphology and glomerular barrier function. Cell 151: 384-399.

Joukov V, Sorsa T, Kumar V, Jeltsch M, Claesson-Welsh L, Cao Y, Saksela O, Kalkkinen N, Alitalo K. 1997. Proteolytic processing regulates receptor specificity and activity of VEGF-C. EMBO J 16: 3898-3911. 
M. Shibuya

Kaplan RN, Riba RD, Zacharoulis S, Bramley AH, Vincent L, Costa C, MacDonald DD, Jin DK, Shido K, Kerns SA, et al. 2005. VEGFR1-positive haematopoietic bone marrow progenitors initiate the pre-metastatic niche. Nature 438: $820-827$.

Karkkainen MJ, Jussila L, Ferrell RE, Finegold DN, Altalo K. 2001. Molecular regulation of lymphangiogenesis and targets for tissue oedema. Trends Mol Med 7: 18-22.

Kendall RL, Thomas KA. 1993. Inhibition of vascular endothelial cell growth factor activity by an endogenously encoded soluble receptor. Proc Natl Acad Sci 90: 10705 10709.

Kerber M, Reiss Y, Wickersheim A, Jugold M, Kiessling F, Heil M, Tchaikovski V, Waltenberger J, Shibuya M, Plate $\mathrm{KH}$, et al. 2008. Flt-1 signaling in macrophages promotes glioma growth in vivo. Cancer Res 68: 7342-7351.

Keyt BA, Nguyen HV, Berleau LT, Duarte CM, Park J, Chen H, Ferrara N. 1996. Identification of vascular endothelial growth factor determinanats for binding KDR and FLT-1 receptors. J Biol Chem 271: 5638-5646

Kiba A, Sagara H, Hara T, Shibuya M. 2003a. VEGFR-2specific ligand VEGF-E induces non-edematous hypervascularization in mice. Biochem Biophys Res Commun 301: 371-377.

Kiba A, Yabana N, Shibuya M. 2003b. A set of loop-1 and -3 structures in the novel VEGF family member, VEGF$\mathrm{E}_{\mathrm{NZ7}}$, is essential for the activation of VEGFR-2 signaling. J Biol Chem 278: 13453-13461.

Kim KJ, Li B, Winer J, Armanini M, Gillett N, Phillips HS, Ferrara N. 1993. Inhibition of vascular endothelia growth factor-induced angiogenesis suppresses tumour growth in vivo. Nature 362: 841-844.

Koga K, Osuga Y, Yoshino O, Hirota Y, Ruimeng X, Hirata T, Takeda S, Yano T, Tsutsumi O, Taketani Y. 2003. Elevated serum soluble vascular endothelial growth factor receptor 1 (sVEGFR-1) levels in women with preeclampsia. J Clin Endocrinol Metab 88: 2348-2351.

Kondo K, Hiratsuka S, Subbalakshmi E, Matsushime H, Shibuya M. 1998. Genomic organization of the flt-1 gene encoding for vascular endothelial growth factor (VEGF) receptor-1 suggests an intimate evolutionary relationship between the 7-Ig and the 5-Ig tyrosine kinase receptors. Gene 208: 297-305.

Kunstfeld R, Hirakawa S, Hong YK, Schacht V, LangeAsschenfeldt B, Velasco P, Lin C, Fiebiger E, Wei X, Wu $\mathrm{Y}$, et al. 2004. Induction of cutaneous delayed-type hypersensitivity reactions in VEGF-A transgenic mice results in chronic skin inflammation associated with persistent lymphatic hyperplasia. Blood 104: 1048-1057.

Lawson ND, Mugford JW, Diamond BA, Weinstein BM. 2003. Phospholipase C $\gamma-1$ is required downstream of vascular endothelial growth factor during arterial development. Genes Dev 17: 1346-1351.

LeCouter J, Moritz DR, Li B, Phillips GL, Liang XH, Gerber HP, Hillan KJ, Ferrara N. 2003. Angiogenesis-independent endothelial protection of liver: Role of VEGFR-1. Science 299: 890-893.

Levine RJ, Maynard SE, Qian C, Lim KH, England LJ, Yu KF, Schisterman EF, Thadhani R, Sachs BP, Epstein FH, et al. 2004. Circulating angiogenic factors and the risk of preeclampsia. N Engl J Med 350: 672-683.
Lohela M, Bry M, Tammela T, Alitalo K. 2009. VEGFs and receptors involved in angiogenesis versus lymphangiogenesis. Curr Opin Cell Biol 21: 154-165.

Lyttle DJ, Fraser KM, Fleming SB, Mercer AA, Robinson AJ. 1994. Homologs of vascular endothelial growth factor are encoded by the poxvirus orf virus. J Virol 68: 84-92.

Mäkinen T, Veikkola T, Mustjoki S, Karpanen T, Catimel B, Nice EC, Wise L, Mercer A, Kowalski H, Kerjaschki D, et al. 2001. Isolated lymphatic endothelial cells transduce growth, survival and migratory signals via the VEGF-C/ D receptor VEGFR-3. EMBO J 20: 4762-4773.

Matsumoto T, Bohman S, Dixelius J, Berge T, Dimberg A, Magnusson P, Wang L, Wikner C, Qi JH, Wernstedt C, et al. 2005. VEGF receptor-2 Y951 signaling and a role for the adapter molecule TSAd in tumor angiogenesis. EMBO J 24: 2342-2353.

Matthews W, Jordan CT, Gavin M, Jenkins NA, Copeland NG, Lemischka IR. 1991. A receptor tyrosine kinase cDNA isolated from a population of enriched primitive hematopoietic cells and exhibiting close genetic linkage to c-kit. Proc Natl Acad Sci 88: 9026-9030.

Maynard SE, Min JY, Merchan J, Lim KH, Li J, Mondal S, Libermann TA, Morgan JP, Sellke FW, Stillman IE, et al. 2003. Excess placental soluble fms-like tyrosine kinase 1 (sFlt1) may contribute to endothelial dysfunction, hypertension, and proteinuria in preeclampsia. J Clin Invest 111: $649-658$.

McColl BK, Paavonen K, Karnezis T, Harris NC, Davydova N, Rothacker J, Nice EC, Harder KW, Roufail S, Hibbs ML, et al. 2007. Proprotein convertases promote processing of VEGF-D, a critical step for binding the angiogenic receptor VEGFR-2. FASEB J 21: 1088-1098.

Murakami M, Iwai S, Hiratsuka S, Yamauchi M, Nakamura K, Iwakura Y, Shibuya M. 2006. Signaling of vascular endothelial growth factor receptor-1 tyrosine kinase promotes rheumatoid arthritis through activation of monocyte/macrophages. Blood 108: 1849-1856.

Muramatsu M, Yamamoto S, Osawa T, Shibuya M. 2010. VEGFR-1 signaling promotes mobilization of macrophage-lineage cells from bone marrow and stimulates solid tumor growth. Cancer Res 70: 8211-8221.

Niida S, Kondo T, Hiratsuka S, Hayashi S-I, Amizuka N, Noda T, Ikeda K, Shibuya M. 2005. Vascular endothelial growth factor receptor-1 signaling is essential for osteoclast development and bone-marrow formation in CSF1-deficient mice. Proc Natl Acad Sci 102: 14016-14021.

Ogawa S, Oku A, Sawano A, Yamaguchi S, Yazaki Y, Shibuya M. 1998. A novel type of vascular endothelial growth factor: VEGF-E (NZ-7 VEGF) preferentially utilizes KDR/ Flk-1 receptor and carries a potent mitotic activity without heparin-binding domain. J Biol Chem 273:31273-31282.

Osawa T, Muramatsu M, Watanabe M, Shibuya M. 2009. Hypoxia and low nutrition double stress induces aggressiveness in a murine model of melanoma. Cancer Sci 100: 844-851.

Risau W. 1997. Mechanism of angiogenesis. Nature 386: 671-674.

Ruhrberg C, Gerhardt H, Golding M, Watson R, Ioannidou S, Fujisawa H, Betsholtz C, Shima DT. 2002. Spatially restricted patterning cues provided by heparin-binding VEGF-A control blood vessel branching morphogenesis. Genes Dev 16: 2684-2698. 
Sakurai Y, Ohgimoto K, Kataoka Y, Yoshida N, Shibuya M. 2005. Essential role of Flk-1 (VEGF receptor 2) tyrosine residue 1173 in vasculogenesis in mice. Proc Natl Acad Sci 102: 1076-1081.

Sase H, Watabe T, Kawasaki K, Miyazono K, Miyazawa K. 2009. VEGFR2-PLC- $\gamma 1$ axis is essential for endothelial specification of VEGFR2 $^{+}$vascular progenitor cells J Cell Sci 122: 3303-3311.

Sawano A, Takahashi T, Yamaguchi S, Aonuma T, Shibuya M. 1996. Flt-1 but not KDR/Flk-1 tyrosine kinase is a receptor for placenta growth factor (PlGF), which is related to vascular endothelial growth factor (VEGF). Cell Growth Diff 7: 213-221.

Sawano A, Iwai S, Sakurai Y, Ito M, Shitara K, Nakahata T, Shibuya M. 2001. Vascular endothelial growth factor receptor-1 (Flt-1) is a novel cell surface marker for the lineage of monocyte-macrophages in humans. Blood 97: 785-791

Shalaby F, Rossant J, Yamaguchi TP, Gertsenstein M, Wu X-F, Breitman ML, Schuh AC. 1995. Failure of blood-island formation and vasculogenesis in Flk-1-deficient mice. Nature 376: 62-66.

Shibuya M. 1995. Role of VEGF-Flt receptor system in normal and tumor angiogenesis. Adv Cancer Res 67: 281-316.

Shibuya M. 2002.Vascular endothelial growth factor receptor family genes: When did the three genes phylogenetically segregate? Biol Chem 383: 1573-1579.

Shibuya M. 2011. Involvement of Flt-1 (VEGFR-1) in cancer and preeclampsia. Proc Jpn Acad Ser B Phys Biol Sci 87: 167-178.

Shibuya M, Claesson-Welsh L. 2006. Signal transduction by VEGF receptors in regulation of angiogenesis and lymphangiogenesis. Exp Cell Res 312: 549-560.

Shibuya M, Yamaguchi S, Yamane A, Ikeda T, Tojo A, Matsushime H, Sato M. 1990. Nucleotide sequence and expression of a novel human receptor-type tyrosine kinase gene (flt) closely related to the fms family. Oncogene $\mathbf{5}$ : 519-524.

Shinkai A, Ito M, Anazawa H, Yamaguchi S, Shitara K, Shibuya M. 1998. Mapping of the sites involved in ligandassociation and dissociation at the extracellular domain of vascular endothelial growth factor receptor KDR. J Biol Chem 273: 31283-31288

Stefater JA III, Lewkowich I, Rao S, Mariggi G, Carpenter AC, Burr AR, Fan J, Ajima R, Molkentin JD, Williams BO, et al. 2011. Regulation of angiogenesis by a non-canonical Wnt-Flt1 pathway in myeloid cells. Nature 474: 511-515.

Takahashi T, Shibuya M. 1997. The $230 \mathrm{kDa}$ mature form of KDR/Flk-1 (VEGF receptor-2) activates the PLC- $\gamma$ pathway and partially induces mitotic signals in NIH3T3 fibroblasts. Oncogene 14: 2079-2089.

Takahashi T, Ueno H, Shibuya M. 1999. VEGF activates protein kinase C-dependent, but Ras-independent RafMEK-MAP kinase pathway for DNA synthesis in primary endothelial cells. Oncogene 18: 2221-2230.

Takahashi T, Yamaguchi S, Chida K, Shibuya M. 2001. A single autophosphorylation site on KDR/Flk-1 is essential for VEGF-A-dependent activation of PLC- $\gamma$ and DNA synthesis in vascular endothelial cells. EMBO J 20: 2768-2778.

Tanaka K, Yamaguchi S, Sawano A, Shibuya M. 1997. Characterization of the extracellular domain in the vascular endothelial growth factor receptor-1 (Flt-1 tyrosine kinase). Jpn J Cancer Res 88: 867-876.

Terman BI, Carrion ME, Kovacs E, Rasmussen BA, Eddy R, Shows TB. 1991. Identification of a new endothelial cell growth factor receptor tyrosine kinase. Oncogene 6: 1677-1683.

Thadhani R, Kisner T, Hagmann H, Bossung V, Noack S, Schaarschmidt W, Jank A, Kribs A, Cornely OA, Kreyssig C, et al. 2011. Pilot study of extracorporeal removal of soluble fms-like tyrosine kinase 1 in preeclampsia. Circulation 124: 940-950.

Tsuchida R, Das B, Yeger H, Koren G, Shibuya M, Thorner PS, Baruchel S, Malkin D. 2008. Cisplatin treatment increases survival and expansion of a highly tumorigenic side-population fraction by upregulating VEGF/Flt1 autocrine signaling. Oncogene 27: 3923-3934.

Veikkola T, Jussila L, Makinen T, Karpanen T, Jeltsch M, Petrova TV, Kubo H, Thurston G, McDonald DM, Achen MG, et al. 2001. Signalling via vascular endothelial growth factor receptor-3 is sufficient for lymphangiogenesis in transgenic mice. EMBO J 20: 1223-1231.

Wang S, Li X, Parra M, Verdin E, Basel-Duby R, Olson EN. 2008. Control of endothelial cell proliferation and migration by VEGF signaling to histone deacetylase 7. Proc Natl Acad Sci 105: 7738-7743.

Wang F, Yamauchi M, Muramatsu M, Osawa T, Tsuchida R, Shibuya M. 2011. RACK1 regulates VEGF/Flt1-mediated cell migration via activation of a PI3K/Akt pathway. J Biol Chem 286: 9097-9106.

Wu Y, Hooper AT, Zhong Z, Witte L, Bohlen P, Rafii S, Hicklin DJ. 2006. The vascular endothelial growth factor receptor (VEGFR-1) supports growth and survival of human breast carcinoma. Int J Cancer 119: 1519-1529.

Xia P, Aiello LP, Ishii H, Jiang ZY, Park DJ, Robinson GS, Takagi H, Newsome WP, Jirousek MR, King GL. 1996. Characterization of vascular endothelial growth factor's effect on the activation of protein kinase $\mathrm{C}$, its isoforms, and endothelial cell growth. J Clin Invest 98: 2018-2026.

Xiong Y, Huo Y, Chen C, Zeng H, Lu X, Wei C, Ruan C, Zhang X, Hu Z, Shibuya M, et al. 2009. VEGF receptor-2 Y1175 signaling controls VEGF-induced vWF release from endothelial cells via PLC- $\gamma 1$ - and PKA-dependent pathways. J Biol Chem 284: 23217-23224.

Yamaguchi S, Iwata K, Shibuya M. 2002. Soluble Flt-1 (soluble VEGFR-1), a potent natural anti-angiogenic molecule in mammals, is phylogenetically conserved in avians. $\mathrm{Bi}$ ochem Biophys Res Commun 291: 554-559.

Yang Y, Xie P, Opatowsky Y, Schlessinger J. 2010. Direct contacts between extracellular membrane-proximal domains are required for VEGF receptor activation and cell signaling. Proc Natl Acad Sci 107: 1906-1911.

You WK, Sennino B, Williamson CW, Falcón B, Hashizume H, Yao LC, Aftab DT, McDonald DM. 2011. VEGF and c-Met blockade amplify angiogenesis inhibition in pancreatic islet cancer. Cancer Res 71: 4758-4768.

Zheng Y, Murakami M, Takahashi H, Yamauchi M, Kiba A, Yamaguchi S, Yabana N, Alitalo K, Shibuya M. 2006. Chimeric VEGF-E $\mathrm{NZ}_{\mathrm{NZ}} / \mathrm{PlGF}$ promotes angiogenesis via VEGFR-2 without significant enhancement of vascular permeability and inflammation. Arterioscler Thromb Vasc Biol 26: 2019-2026. 


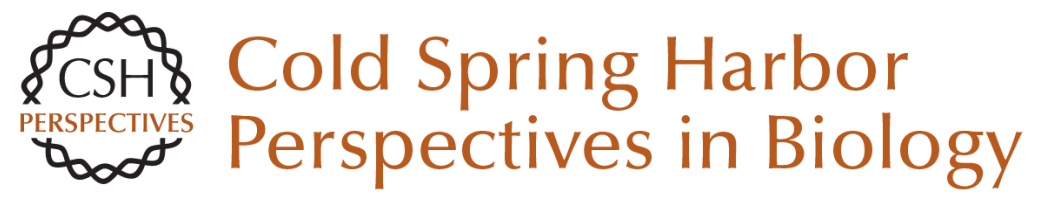

\section{VEGFR and Type-V RTK Activation and Signaling}

Masabumi Shibuya

Cold Spring Harb Perspect Biol 2013; doi: 10.1101/cshperspect.a009092

Subject Collection Signaling by Receptor Tyrosine Kinases

CSF-1 Receptor Signaling in Myeloid Cells

E. Richard Stanley and Violeta Chitu

The EGFR Family: Not So Prototypical Receptor Tyrosine Kinases

Mark A. Lemmon, Joseph Schlessinger and Kathryn M. Ferguson

Tie2 and Eph Receptor Tyrosine Kinase Activation and Signaling

William A. Barton, Annamarie C. Dalton, Tom C.M. Seegar, et al.

The Spatiotemporal Organization of ErbB

Receptors: Insights from Microscopy

Christopher C. Valley, Keith A. Lidke and Diane S. Lidke

Insulin Receptor Signaling in Normal and Insulin-Resistant States

Jérémie Boucher, André Kleinridders and C. Ronald Kahn

Central Role of RET in Thyroid Cancer Massimo Santoro and Francesca Carlomagno

Receptor Tyrosine Kinase-Mediated Angiogenesis Michael Jeltsch, Veli-Matti Leppänen, Pipsa Saharinen, et al.

Biology of the TAM Receptors Greg Lemke
The Genesis of Tyrosine Phosphorylation Tony Hunter

Structure-Function Relationships of ErbB RTKs in the Plasma Membrane of Living Cells

Donna J. Arndt-Jovin, Michelle G. Botelho and Thomas M. Jovin

Receptor Tyrosine Kinases: Legacy of the First

Two Decades Joseph Schlessinger

The Role of Ryk and Ror Receptor Tyrosine Kinases in Wnt Signal Transduction Jennifer Green, Roel Nusse and Renée van Amerongen

Regulation of Receptor Tyrosine Kinase Ligand Processing Colin Adrain and Matthew Freeman

Molecular Mechanisms of SH2- and PTB-Domain-Containing Proteins in Receptor Tyrosine Kinase Signaling Melany J. Wagner, Melissa M. Stacey, Bernard A. Liu, et al.

Eph Receptor Signaling and Ephrins Erika M. Lisabeth, Giulia Falivelli and Elena B. Pasquale

Effects of Membrane Trafficking on Signaling by

Receptor Tyrosine Kinases Marta Miaczynska

For additional articles in this collection, see http://cshperspectives.cshlp.org/cgi/collection/

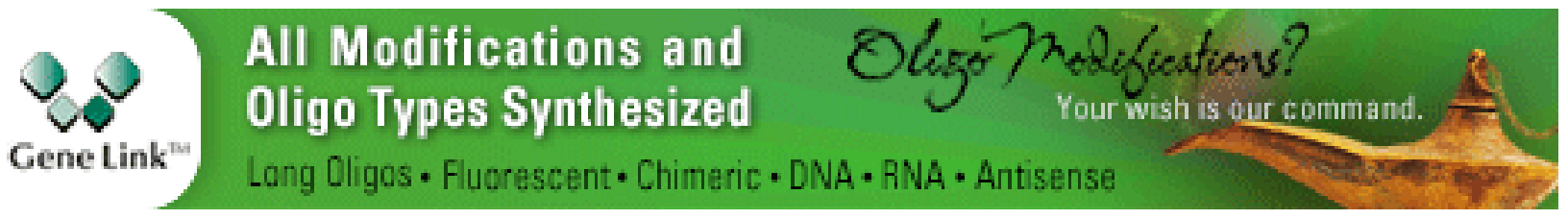


For additional articles in this collection, see http://cshperspectives.cshlp.org/cgi/collection/

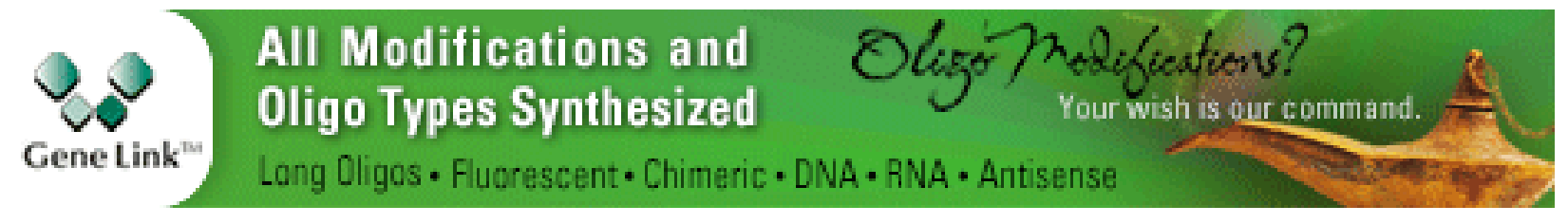

Copyright @ 2013 Cold Spring Harbor Laboratory Press; all rights reserved 